\title{
Torsion of the normally positioned spleen
}

\author{
Haiyuan Shi, ${ }^{1}$ Ehab Shaban Mahmoud Hamouda ${ }^{2}$
}

'Department of Radiology, Singapore General Hospital, Singapore, Singapore

${ }^{2}$ KK Women's and Children's Hospital, Singapore, Singapore

Correspondence to Dr Haiyuan Shi,

haiyuan.shi@mohh.com.sg

Accepted 5 April 2016

\section{DESCRIPTION}

A 19-year-old autistic woman presented with acute upper abdominal pain, loss of appetite and fever.

Abdominal ultrasound revealed a large complex hypoechoic and avascular structure in the left hypochondrium (figures 1 and 2), at the expected position of the spleen.

CT of the abdomen showed that this mass corresponded to an enlarged and non-enhancing spleen (figure 3 ) that was twisted around its vascular pedicles (figure 4).

Emergency laparotomy found an engorged and infarcted spleen that was twisted anticlockwise around its pedicles. The spleen was normal in position, located between the stomach and left hemidiaphragm, however, the main splenic ligaments were largely absent (eg, the splenophrenic and gastrosplenic ligaments).

Splenic torsion is extremely rare, with one study citing a prevalence of $0.3 \%{ }^{1}$ among 1413 splenectomised patients. It is a known complication of a

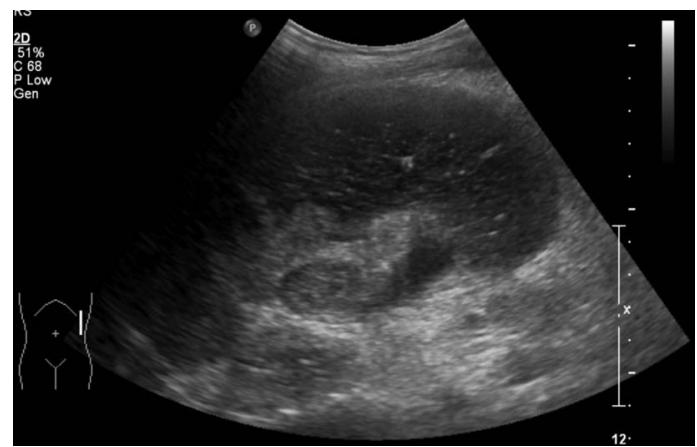

Figure 1 Ultrasound shows a spleniform hypoechoic mass with hyperechoic hilum.

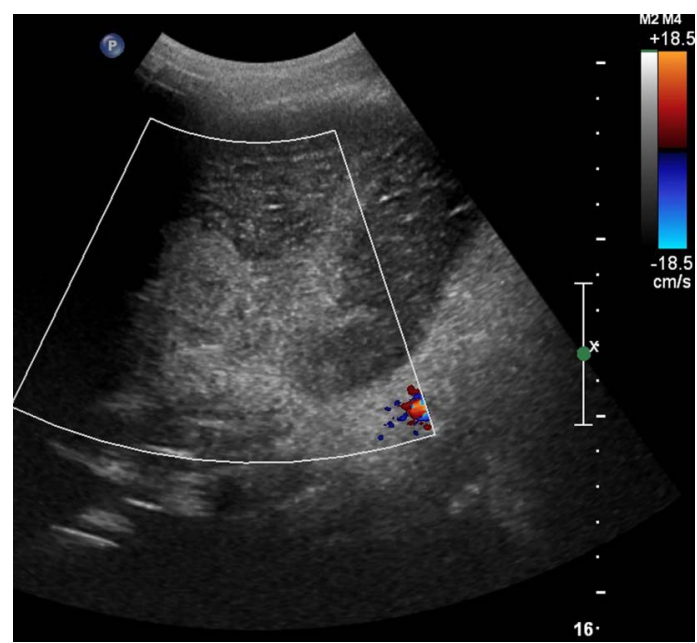

Figure 2 Doppler ultrasound fails to demonstrate vascularity at the splenic hilum.

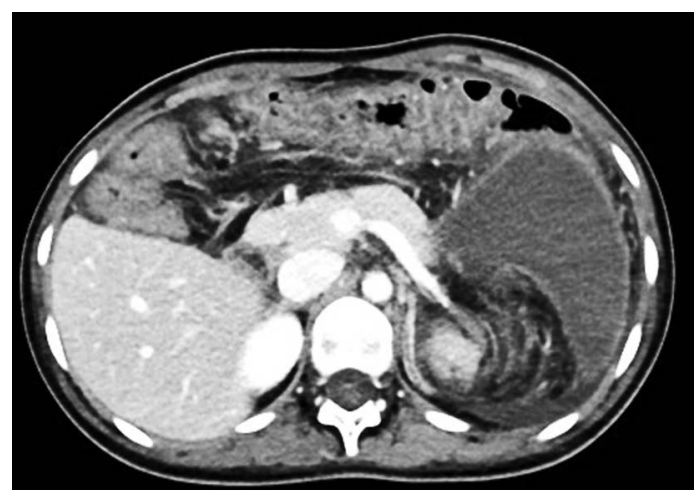

Figure 3 Coronal CT shows a normal positioned spleen that is enlarged and hypodense, corresponding to the hypoechoic mass seen on ultrasound.

hypermobile or 'wandering' spleen, which may twist around itself because of the lack of normal stabilising splenic ligaments and elongated vascular pedicle. Therefore, in most cases of splenic torsion, one would also expect to find the spleen in an ectopic position, usually in the left lower abdomen. To the knowledge of the authors, there has only been one reported case of torsion of a normalpositioned spleen. $^{2}$

The infarcted spleen appears enlarged, hypoechoic on ultrasound and hypodense on contrast-enhanced CT. Identification of the highly specific whorled appearance ${ }^{3}$ of the splenic vascular pedicles will pinpoint the aetiology to that of torsion (figure 4).

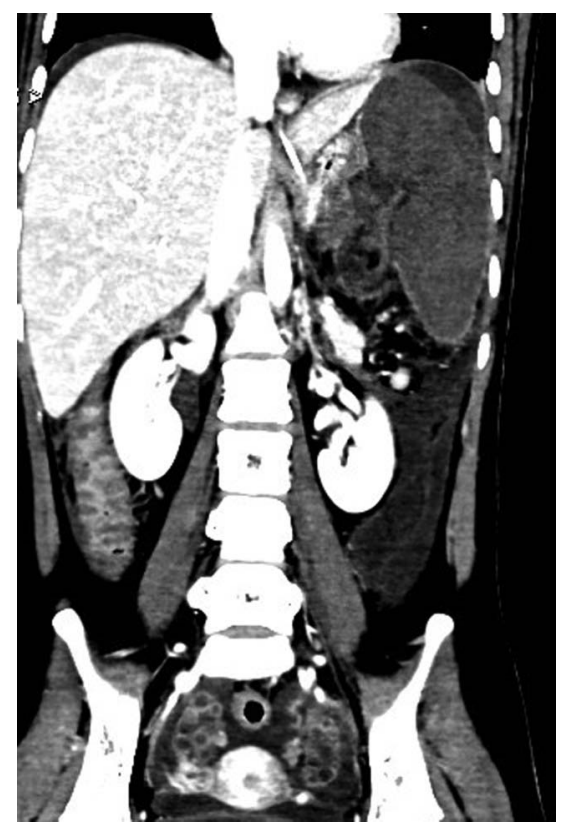

Figure 4 Axial CT shows whorled vascular pedicles leading into the splenic hilum. 


\section{Learning points}

Splenic torsion (with subsequent infarction) is a rare cause for left-sided abdominal pain.

- Although splenic torsion is usually found in the hypermobile and ectopic spleen, it may also occur in a normally positioned spleen.

- The whorled sign representing a twisted vascular pedicle at the splenic hilum is highly specific.
Contributors Images provided by KK Women's and Children's Hospital, Singapore. Competing interests None declared.

Patient consent Obtained.

Provenance and peer review Not commissioned; externally peer reviewed.

\section{REFERENCES}

1 Eraklis AJ, Filler RM. Splenectomy in childhood: a review of 1,413 cases. J Pediatr Surg 1972;7:382-8.

2 Helvind NM, Gögenur I, Stadeager M. Splenic torsion as cause of acute abdomen in children. Ugeskr Laeger 2013;175:587-8.

3 Swischuk LE, Williams JB, John SD. Torsion of wandering spleen: the whorled appearance of the splenic pedicle on CT. Pediatr Radiol 1993;23:476-7.

Copyright 2016 BMJ Publishing Group. All rights reserved. For permission to reuse any of this content visit http://group.bmi.com/group/rights-licensing/permissions.

BMJ Case Report Fellows may re-use this article for personal use and teaching without any further permission.

Become a Fellow of BMJ Case Reports today and you can:

- Submit as many cases as you like

- Enjoy fast sympathetic peer review and rapid publication of accepted articles

- Access all the published articles

- Re-use any of the published material for personal use and teaching without further permission

For information on Institutional Fellowships contact consortiasales@bmjgroup.com

Visit casereports.bmj.com for more articles like this and to become a Fellow 